\title{
Study on the Innovative Development of Korean Language Teaching in Universities in the Background of Quality Education
}

\author{
Cheng Lyu \\ School of Foreign Languages, Xi'an University, 710000
}

\begin{abstract}
Keywords: Korean Language Teaching; Regional Culture; Teaching Innovation; Problem Research; Interactive Communication
\end{abstract}

\begin{abstract}
With the implementation and development of reform and opening up, more and more Sino-foreign joint ventures have emerged. Many South Korean companies and Chinese companies have continued to establish sustainable cooperation so that both parties have achieved economic development. In addition, under the impetus of the Internet, Korea's film and television, clothing and food culture have gradually infiltrated into China, which has made Korean language more widely known and recognized in China. More and more Chinese people are beginning to like Korean, coupled with the need for exchanges in different fields and areas between China and South Korea, which has increased the demand for professional Korean professionals. As a result, many colleges and universities have conducted Korean language teaching. Under such an era, training high-quality Korean language talent has become an important task for colleges and universities.
\end{abstract}

\section{The Main Problems in College Korean Teaching}

In terms of cultural inclusiveness and diversity in our country, there is nothing wrong with the need for colleges and universities to develop Korean language teaching. However, many colleges and universities still have some outstanding problems in Korean language teaching due to the short history of the introduction of this language teaching and lack of teaching experience and practice. These problems are not conducive to improving the teaching efficiency of Korean and the quality of students' learning, and it is not conducive to making this teaching more deeply explore the deep culture of language. The following will focus on the status to analyse the main problems in the Korean language teaching in colleges and universities.

Lack of flexible use of Korean language teaching materials. Similar to the problem of most teaching modes, Korean language teaching is often difficult to get rid of the constraints of textbooks. These teaching materials are usually compiled by different Korean professional scholars in the industry based on years of teaching experience and rich language knowledge system. Its purpose is mainly to focus on the content rather than the way of teaching, and the content is relatively traditional and lacks innovative elements. However, most college teachers are once restricted by teaching materials in teaching, and they emphasize on rigorous interpretation of content, lacking flexibility and innovation. And because of the different influences of the infrastructure, teaching methods, and teaching environment of each university, this kind of teaching mode is more difficult to give students a deeper level of understanding. The rigid teaching method will easily cause the course to be boring, and it will cause students to lose interest in it in the long run.

Overemphasizing Grammar Training and Ignoring Practice. For any discipline, practice is undoubtedly the quickest and best way to get information. To focus on theory and practice lightly will easily lead to certain difficulties in the final practical application. And this way of people's thinking can easily cause a certain degree of imprisonment, making it difficult to switch flexibly in later periods. Many colleges and universities have excessively valued grammar in the Korean language teaching process. They test and improve the students' Korean proficiency through written examinations, and neglect students' practice in practical application. Even though grammar is important, excessive grammar rules will easily reduce students' interest in learning Korean, making it difficult to master Korean knowledge more comprehensively and systematically. Moreover, with respect to the written language of the language, too strict grammar rules may cause obstacles in the oral communication and make it difficult to implement flexible transition of thinking. 
Insufficient Teachers and Single Team Structure. Since the history of Korean language majors in Chinese universities is not long, the construction level of Korean professional degree points is still relatively low compared with other popular languages. At present, major universities and colleges in China have few master and doctoral degrees for Korean majors, and they also appear to be narrower in research space and research direction. In addition, in most colleges and universities in Korean language teaching, teachers' resources are insufficient and healthy competition is lacking. In any discipline, teachers play a guiding role in teaching, so their own professional standards or qualities have a direct or indirect impact on students. However, most colleges and universities lack a strong team of teachers and do not have enough teacher resources and practical experience to cope with the increasing number of students and teaching needs that have been expanding year by year. Therefore, students are unable to learn sufficient Korean knowledge and master the use of Korean language in their lives, which is extremely detrimental to student's learning achievement and the improvement of college teaching quality.

Single and Boring Teaching Mode. The original intention of most students to choose the Korean language is to love Korean culture rather than Korean grammar. However, most of the current Korean language teaching modes present a single structural mode that from the silent backsliding of words to the interpretation of example sentences then to taking notes in a formative manner. It quickly weaken the enthusiasm of students when they begin to learn Korean, making it difficult to persevere in the learning process. With the complex knowledge structure of Korean, this traditional teaching mode has made students gradually become passive and dependent. They just mechanically accept content and ignore their own comprehensive ability training in listening and speaking, which not only reduces the quality of Korean language teaching, but also has a negative impact on their enthusiasm both teachers and students.

\section{Research on the Innovation of Korean Teaching in Universities}

Nowadays, the application fields of Korean are becoming more and more widespread in China, and it has been difficult for Korean language teaching to develop side by side with it. With the problems faced by Korean language teaching in the university teaching system, this article will try to give corresponding countermeasures to the above questions.

Using Multimedia Teaching to Improve the Flexibility of Teaching Materials. Compared with traditional textbooks, multimedia teaching is more likely to stimulate an active classroom learning atmosphere in teaching. Because Korean language and Chinese language have certain differences in language logic and expression thinking, beginners often have great curiosity and interest in it. As a teacher, how to help students retain this interest in long-term teaching is very important. The traditional textbook content and boring learning atmosphere tend to quickly eliminate this interest and curiosity. The traditional textbook content and the boring learning atmosphere tend to consume this interest and curiosity quickly. Therefore, the use of multimedia teaching is a very effective method to master Korean knowledge. In multimedia teaching, teachers can select the image material that is close to real life, and effectively improve students' listening in a virtual practice scenario. By repeatedly stimulating the students' listening habits, they gradually adapt to the auditory thinking of Korean. This helps students to understand the content of teaching materials and can flexibly combine grammar and application, which can not only improve students' interest in learning, but also help students to improve their Korean language to the greatest extent possible.

Pay Attention to the Cultivation of Practical Ability. In the teaching of Korean language in colleges and universities, the key to changing the traditional concept of Korean language teaching is to innovate the teaching concepts of Korean language. The traditional teaching mode does not apply to the demand of the society for Korean nowadays. This social demand requires that college students have good practical application capabilities. Therefore, teachers should flexibly use various innovative teaching methods in the teaching process, such as the use of multimedia courseware or online resources, to carry out targeted and interesting curriculum guidance and enhance students' ability to think independently. Besides, teachers can integrate other types of interesting nonverbal 
communication methods, such as singing, drama and performance, into Korean language teaching as a medium. At the same time, according to the implementation of teaching objectives, teachers can set up a number of Korean knowledge contests or Korean language simulation scenarios and other aspects of game to improve students' interest in learning Korean. In addition, teachers should help students form Korean language expressions and ways of thinking from life, learning and behavior. Through student's own life practice, they can acquire more Korean language proficiency in mutual learning, so that they can use it flexibly and consistently and continuously improve their practical application of Korean.

Expand Teacher Resources, Establish Training Institutions and Combine Universities with Training Institutions. In today's society, practical application talents have been continuously recognized and favored by various industries. Therefore, when developing Korean language teaching in colleges and universities, students should focus on cultivating their practical skills. Blindly teaching theoretical knowledge and ignoring substantive applications will only lead to teaching results without practical skills. Therefore, teachers should pay attention to the integration of Korean theoretical knowledge and practical application for every college and university, and actively develop a teacher-oriented, student-centered classroom mode. Teachers and students should persist in using Korean to communicate and help students to build a Korean language thinking mode and strengthen students' love of Korean language. The resources of Korean teachers in universities are deficient and the teaching mode is relatively traditional, which requires the establishment of professional training institutions. For example, the training base for Korean language training can be established in Korea and each student's learning situation and learning ability can be guided according to the different practical training conditions of each university student. This kind of educational mode that integrates Korean language training with Korean native culture can not only improve students' basic knowledge of Korean language learning, but also can enhance students' ability to widely use Korean language in social practice.

In addition to actively innovating teaching methods and increasing the opportunities for teacher-student interaction and practice, the teacher team should also incorporate new teaching concepts into each student's thinking. Students are encouraged to follow the thinking of the overall teaching system in learning Korean and actively mobilize the subjective initiative so that they can find and solve problems on their own, master more flexible self-study skills and enhance their ability to learn independently. Besides, students should develop good habits of independent learning in practice. For example, teachers can carry out interesting vocabulary games or oral practice activities in the classroom. With role-playing methods, each student can inspire their interest in Korean language learning by freely entering roles. In addition, the extra-curricular activities outside the classroom that are conducive to physical and mental learning are equally important for students to maintain interest in learning Korean. The advanced and interesting teaching mode is conducive to the establishment of an equal and harmonious relationship between teachers and students, so as to strengthen mutual trust and interaction and form a happy and democratic teaching process. At the same time, it also allows students to exercise their social skills in extra-curricular activities so that students can gradually develop independent learning methods.

Combine Korean Language Teaching with Korean Culture to Deepen Understanding. Language plays a role as an interpreter and communicator in the overall social culture. That is to say, the relationship between culture and language is inseparable. In the social context of the same era, the two complement and penetrate each other. Every country's culture has its own commonalities and differences. Therefore, when teachers of higher education are engaged in Korean language teaching, they should focus on associating Korean culture with Korean language teaching, allowing students to understand Korean ways of thinking more deeply by deeper understanding of Korean culture. Korean language teaching starting with Korean culture can help to retain the initial interests of most Korean students who are interested in Korean culture. Through the exploration of Korean food, clothing, etiquette, traditional culture and other topics and its relationship with Korean expression, college students are encouraged to profoundly understand the source of Korean language development and structure. At the same time, it enhances students own cultural qualities 
and insights. In addition, where economic or other conditions permit, universities can strengthen the exchange of China and South Korea. For example, teachers from South Korea' s native universities may be invited to attend classes in China, or Korean teachers from universities may be sent to South Korea for training. In the process of mutual exchanges, the two sides deepened their understanding of each other at the cultural level. Thereby teachers can put Korean culture into the teaching philosophy, which will open up students' visions and increase their Korean cultural literacy in Korean language teaching. Besides, an objective understanding of cultural differences between China and South Korea is also necessary in Korean language learning. Teachers should use Korean as a language to teach and integrate organically with Korean culture and education to consciously guide students to increase their sensitivity to cultural differences between China and Korea. Therefore, teachers must constantly improve their knowledge of Korean culture in the process of Korean language teaching. At the same time, teachers should innovate teaching methods based on different perceptions of various levels of Korean culture. In this way, teachers will be able to explain more knowledge of Korean culture to students in a more meticulous and comprehensive manner, so as to improve students' deep understanding of Korean language.

\section{Conclusion}

In the Korean language teaching in universities, traditional teaching concepts and methods have been unable to adapt to the new demands of Korean development for social development. Therefore, teachers should take the initiative to innovate in the process of teaching Korean, move out of the old teaching models and concepts and step out of the framework of Korean textbooks. Teachers should focus on linking practical applications with theoretical knowledge to make the curriculum more flexible and expandable. At the same time, it is necessary to actively expand the teachers team in colleges and universities, improve teachers' teaching quality and cultivate teachers' teaching thinking modes that keep pace with the times.

\section{Reference}

[1] J. Tian. Korean Culture Theory. Sun Yat-sen University Press. 2010.

[2] J. C. Lin. Understanding of Korean Culture. Dalian Press. 2012.

[3] M. A. Zhu, D. G. Jin, Y. L. Yu, B. Y. Zhang and X. M. Zong. Korean Society and Culture. Foreign Language Teaching and Research Press. 2017.

[4] Y. L. Chen. Succession and Integration. Central Compilation Press. 2017.

[5] B. X. Long. Teacher Education and Cultural Innovation Research. Education Science Press. 2009.

[6] Q. Zhang. Practical Korean Grammar - Detailed Explanation and Exercises. China Aerospace Press. 2012.

[7] IBM Global Business Services (South Korea). Translated by X. L. Jin. Into Korea. China Railway Press. 2009.

[8] Yonsei University Korean Language School (South Korea). Yonsei Korean. World Book Publishing Company. 2014.

[9] Shui Ye junping. The Story of Korea. China Friendship Publishing Company. 2016.

[10] Seoul National University Korean Language Education Institute. Translated by Y. H. Sun. Seoul National University Korean. Foreign Language Teaching and Research Press. 2008. 